\title{
NUEVOS RETOS DE LAS PRESTACIONES DE LA SEGURIDAD SOCIAL POR MATERNIDAD Y PATERNIDAD
}

\section{New challenges of the Social Security maternity and paternity benefits}

\author{
JULEN LLORENS ESPADA \\ Profesor Asociado de Derecho del Trabajo y de la Seguridad Social \\ Universidad Pública de Navarra-Nafarroako Unibertsitate Publikoa
}

\section{ABSTRACT}

En el presente trabajo se realiza un estudio del estado actual de las prestaciones de la Seguridad Social por maternidad y paternidad, diez años después de la promulgación de la LOI. Ello se realiza desde una visión integradora de la más reciente doctrina jurisprudencial nacional y europea, lo cual lleva el estudio a supuestos de actual litigiosidad como el disfrute del permiso de maternidad por «el otro progenitor» o los casos de maternidad subrogada y el reconocimiento de las prestaciones de maternidad para estos casos. Con todo ello, el estudio pretende arrojar algo de luz en el camino hacia un marco equitativo de corresponsabilidad e involucración efectiva de ambos sexos.

Palabras clave: maternidad; paternidad; corresponsabilidad; discriminación; gestación subrogada.

Honako lanean, Emakumeen eta Gizonen Berdintasun Eragingarrirako Lege Organikoaren aldarrikapenetik 10 urte betetzen direlarik, Gizarte Segurantzaren amatasun eta aitatasun prestazioen gaur egungoko egoera ikertzen da. Hau, bai eu- 
ropar bai nazional mailako azkeneko jurisprudentziaren ikuspegi integratzaile batekin jorratzen da, hortaz, azterketa gaur egun auzitegietan aurkitzen diren arazoetara eramango da, esate baterako, amatasun prestazioa "beste gurasoa"-k noiz izan ahalko duen edota amatasun subrogatua eta hauendako prestazioen onarpena bezalako gaiak landuz. Guzti honekin, ikerketa erantzunkidetasunaren eta bi sexuen partehartze eraginkorraren bidezko esparruarentzako norabidean argitasuna ematen saiatuko da.

Hitz gakoak: amatasuna; aitatasuna; erantzunkidetasuna; bereizkeria eta ordezko ernaldia.

Ten years after the enactment of the "LOI», the present essay carries out a study of the current situation of the Social Security's maternity and paternity benefits. The analysis comprehends the most recent national and European jurisprudential doctrine, whereof the study of current litigious scenarios such as the entitlement of the "other progenitor» to benefit from maternity leave or cases of surrogate parenthood and the allocation of social benefits in these cases. Thus, this paper tries to cast light on a path leading towards a fair framework of co-responsibility and effective implication of both genders

Keywords: Maternity, paternity, co-responsibility, discrimination, surrogacy. 


\section{SUMARIO}

1. Planteamiento inicial. 2. El permiso de maternidad y sus prestaciones: 2.1. Situación protegida 2.1.1. Suspensión por maternidad biológica: embarazo, parto y puerperio 2.1.2. Suspensión por maternidad por adopción o acogimiento 2.2. Titularidad 2.2.1. Maternidad biológica 2.2.2. Maternidad por adopción o acogimiento 2.2.3. Maternidad subrogada. 3. El permiso de paternidad y sus prestaciones 3.1. Situación protegida 3.2. Titularidad. 4. Reflexiones finales. 5. Bibliografía.

\section{Planteamiento inicial}

Transcurridos diez años desde la promulgación de la Ley Orgánica 3/2007, de 22 de marzo, para la igualdad efectiva de mujeres y hombres, se presenta necesario un análisis reflexivo sobre los avances que en materia de igualdad se han derivado de ella, pero sobre todo, deviene necesario un estudio de los nuevos interrogantes que la realidad social muestra y del modo en que el marco normativo responde ante estos nuevos retos.

En ese sentido, factores como las nuevas formas o estructuras familiares o las diferentes formas de gestación de los recién nacidos, quiebran los cánones clásicos y generan nuevas escenarios. Desde el prisma de la búsqueda de la igualdad efectiva entre hombres y mujeres, el estudio obliga a focalizar en las posibles discriminaciones por razón de sexo que con estos nuevos paradigmas pueden presentarse.

De esa manera, en lo que a las prestaciones de la Seguridad Social se refiere, convergen disyuntivas clásicas a las que sigue sin darse solución junto a otras novedosas que requieren de un mayor estudio en toda su complejidad.

El estudio de las prestaciones y las posibles concurrencias de situaciones discriminatorias conlleva que el estudio se dirija a un análisis de los bienes jurídicos protegidos con cada prestación pública, ya que sólo así puede discernirse con claridad el propósito con el que cada prestación se configura y entender el papel que cada sujeto titular desempeña en consecuencia.

Por ello, las próximas líneas se focalizan en el bien jurídico a salvaguardar y los sujetos titulares de las prestaciones que vienen a protegerlo, para así poder 
localizar los puntos débiles de una normativa que no siempre logra encaminar la realidad hacia un marco de corresponsabilidad de los progenitores, hacia un marco de reparto equitativo de funciones respecto de las cargas familiares, a la vez que se logra garantizar un correcto espacio de conciliación de la vida laboral y familiar.

\section{El permiso de maternidad y sus prestaciones}

El art. 45.1.d) del Real Decreto Legislativo 2/2015, de 23 de octubre, por el que se aprueba el texto refundido de la Ley del Estatuto de los Trabajadores (en adelante, ET) establece que la maternidad, paternidad, adopción, guarda con fines de adopción o acogimiento, serán posibles causas para la suspensión del contrato de trabajo. En ese sentido, la primera consecuencia que a efectos laborales se genera como consecuencia de la maternidad será precisamente la suspensión del contrato de trabajo, en tanto la trabajadora encuentra como derivación de su estado de salud una necesidad de interrumpir la prestación de trabajo, y por ende, decae entonces el deber sinalagmático de retribución de la prestación de servicios. En este escenario, se entiende que el marco tuitivo erigido sobre la mujer trabajadora vaya dirigido al mantenimiento del empleo durante ese período, la preservación de los ingresos en tanto se prolongue la cesación de servicios, así como a garantizar que la trabajadora conserve durante ese período sus derechos profesionales sin recibir ninguna desventaja por ello ${ }^{1}$.

De esa manera, la prestación por maternidad aparece como la cobertura que la Seguridad Social brinda durante el período en el que la persona trabajadora se encuentre inmersa en el uso del permiso de maternidad. Ante la suspensión del contrato de trabajo como consecuencia del permiso de maternidad, aparece la prestación para garantizar el sustento económico ante tal suspensión. Existe una relación de causa-efecto entre ambos conceptos, una interrelación entre permiso y prestación, de modo que siempre que haya una prestación habrá un permiso subyacente; ahora bien, siempre que haya un permiso no habrá una prestación, como luego se verá. Dentro de los supuestos que darán lugar al permiso por maternidad nuestro legislador ha diferenciado entre el parto, la adopción y el acogimiento.

Desde una perspectiva de género, cuando de los permisos de maternidad y paternidad se trata, una mirada crítica debe dirigir el foco de atención al bien jurídico protegido en cada supuesto, así como a la titularidad del permiso en cuestión (Sierra, 2017: 10).

${ }^{1}$ STC núm. 162/2016, de 3 de octubre. 


\subsection{Situación protegida}

\subsubsection{Suspensión por maternidad biológica: embarazo, parto y puerperio}

Con el término embarazo se alude al estado en el que se encuentra la mujer gestante desde la concepción hasta el parto. En una primera mirada, la prestación por maternidad no parece que se encuentre encaminada a la protección de la «mera gestación», dada la concurrencia de otros mecanismos protectores a los que la mujer embarazada puede encontrar protección, como son la suspensión por riesgo durante el embarazo o la propia suspensión como advenimiento de una incapacidad temporal.

Ahora bien, no resultaría acertado desatender a las posibles fracturas que estos mecanismos pueden presentar, generando que no siempre pueda la trabajadora acceder a ellas. Para el primero de los supuestos, deberá concurrir un riesgo específico que pueda repercutir negativamente sobre el estado de salud de la trabajadora o del feto, a lo que se suma que la necesaria adaptación del puesto o el cambio de puesto no resulte técnica u objetivamente posible o no pueda razonablemente exigirse por motivos justificados (art. 26.2 y 3 de la Ley 31/1995, de 8 de noviembre, de Prevención de Riesgos Laborales, en adelante, LPRL). La no exigencia de períodos previos de cotización y la utilización de la Base Reguladora relativa a la cobertura de contingencias profesionales, hacen de esta vía la idónea para la protección de la trabajadora embarazada. No obstante, cuando no sea posible su disfrute, como puede ser el caso de que la incapacidad provenga de un riesgo de origen no profesional, podrá la trabajadora acogerse a la suspensión por incapacidad temporal, si bien, deberá entonces atenerse a los requisitos generales propios de las prestaciones por contingencias comunes, con un período de cotización previa no inferior a los 180 días en los 5 años inmediatamente anteriores, para disfrutar de unas prestaciones inferiores a las del supuestos anterior, por quedarse los 3 primeros días de la contingencia sin cobertura, y ser las bases reguladoras de menor importe.

De todo ello, se entiende que en ocasiones deban las trabajadoras embarazadas acogerse necesariamente a la prestación por maternidad, y disfrutar en fecha previa al "parto» de una parte de las dieciséis semanas que el art. 48.4 ET reconoce como descanso por este concepto para el trabajo estatutario, y el permiso que en iguales términos prevé el art. 49 del Real Decreto Legislativo 5/2015, de 30 de octubre, por el que se aprueba el texto refundido de la Ley del Estatuto Básico del Empleado Público (en adelante, EBEP). De estas dieciséis semanas de suspensión ininterrumpida, ampliables en dos semanas por parto múltiple y a partir da cada hijo o por nacimiento de hijo con discapacidad, seis corresponderán al descanso obligatorio inmediatamente posterior al parto, mientras que el resto del período de suspensión "podrá distribuirse a opción de la interesa». Como queda dicho, el disfrute de los descansos contemplado por la normativa estatu- 
taria para con las situaciones protegidas de maternidad, adopción, la guarda con fines de adopción y el acogimiento familiar, darán lugar a la percepción del subsidio por maternidad (arts. 177 y ss. del Real Decreto Legislativo 8/2015, de 30 de octubre, por el que se aprueba el texto refundido de la Ley General de la Seguridad Social, en adelante, LGSS).

La finalidad de la protección otorgada por el permiso de maternidad es doble, en tanto el bien jurídico en peligro no es único. La prestación dirigida a cubrir la maternidad biológica busca primordialmente preservar la salud de la madre trabajadora ante un hecho biológico singular, ya que una pronta reincorporación al puesto de trabajo podría resultar perjudicial para su recuperación. Junto al bien jurídico que representa la salud de la madre, debe garantizarse que la trabajadora no sufra una merma en sus derechos profesionales como consecuencia de hacer valer la suspensión contractual. Y a ello, añade la doctrina del alto Tribunal otros intereses "dignos de protección» como la «lactancia natural y la especial afectividad entre la madre y el neonato». Sorprende en este sentido que tanto la doctrina jurisprudencial del Tribunal de Justicia de la Unión Europea (en adelante, TJUE) como el Tribunal Supremo (en adelante, TS) cuando la hace suya, mantengan la especial relación afectiva que une al hijo con su madre como interés jurídico a proteger con el permiso de maternidad, con el consiguiente rol discriminatorio que ello conlleva respecto al papel de la madre en la crianza de los hijos, y su percepción de sujeto con mayor aptitud derivada de su condición de mujer ${ }^{2}$.

La integridad física de la madre y su completa recuperación queda protegida mediante el establecimiento de un plazo de seis semanas de permiso obligatorio tras el parto, período indisponible que no podrá ser cedido al otro progenitor. Resulta evidente que, a día de hoy, sólo la mujer puede ser beneficiaria de estas seis semanas, no encontrándose sentido en que su disfrute fuese cedido en tanto con el mismo se busca la recuperación del estado físico generado por el alumbramiento. No obstante, para el restante período comprendido dentro del permiso, el bien jurídico a proteger será en exclusiva la proporción al niño de los primeros cuidados requeridos en sus primeros días de vida. Respecto de las diez semanas restantes, o las semanas que resten en caso de que se haya iniciado su disfrute previo al parto, podrán ser cedidos en su totalidad o parcialmente al otro progenitor para que haga uso de ellos, bien de forma simultánea o sucesiva con la madre. Esta posibilidad resulta coherente con un sistema de conciliación en el que no es la madre la encargada de suministrar esta primera asistencia, sino el progenitor que las partes consideren más adecuado.

2 STC 75/2011, de 19 de mayo de 2011; STC 152/2011, de 29 de septiembre de 2011. 
Acorde a la finalidad de proteger la recuperación física de la madre, la norma sitúa el momento del inicio de las seis semanas dirigidos a este fin a partir del parto, sin que el fallecimiento del hijo pueda dar lugar a la reducción de este período (art. 8.4 Real Decreto 295/2009, de 6 de marzo, por el que se regulan las prestaciones económicas del sistema de la Seguridad Social por maternidad, paternidad, riesgo durante el embarazo y riesgo durante la lactancia natural). Ahora bien, en el caso de que acontezca una interrupción del embarazo, ya sea intencionada o espontanea, ésta únicamente dará lugar al inicio de la prestación cuando el hijo gestante hubiera permanecido en el seno materno durante un período mínimo de ciento ochenta días, frontera temporal criticada en la doctrina por dificultar el acceso a la prestación incongruentemente, más si cabe, cuando se compara con la protección que el sistema dispensa ante situaciones equiparables (Fernández, 2013: 34-37).

\subsubsection{Suspensión por maternidad por adopción o acogimiento}

El permiso por maternidad cubre también los casos de adopción, de guarda con fines de adopción y de acogimiento (art. 48.5 ET). A ello, se le ańadirá la situación de tutela "cuando el tutor sea un familiar que, de acuerdo con la legislación civil, no pueda adoptar al menon» (art. 2.1 RD 295/2009). El subsidio por maternidad en estos casos queda, al igual que en el supuestos de maternidad biológica, ligado al período de descanso que por tales situaciones se disfrute (art. 177 LGSS).

En estos supuestos, el bien jurídico a proteger no será la recuperación de un estado físico tras el alumbramiento sino la asistencia necesaria del hijo en sus primeros momentos tras el hecho jurídico causante. No hay un hecho físico como el alumbramiento de la maternidad biológica, sino un hecho jurídico consistente en una resolución judicial por la que se constituye la adopción o una decisión administrativa de guarda con fines de adopción o de acogimiento.

\subsection{Titularidad}

Para el estudio del permiso por maternidad y la consiguiente prestación económica se deben diferenciar, nuevamente, los supuestos de maternidad biológica y los relativos a adopción y acogimiento, con motivo de su diversa configuración.

\subsubsection{Maternidad biológica}

En la legislación laboral, el art. 48.4 ET configura la suspensión por parto como un derecho de titularidad materna, en tanto prevé que para la distribución del disfrute se atenderá a la "opción de la interesada». No obstante, se prevé la posibilidad de que en algunos supuestos el disfrute pueda derivarse al "otro 
progeniton, con indiferencia del sexo de éste. Entre los supuestos que dan lugar al disfrute por el otro progenitor aparece previsto el caso de fallecimiento de la madre, el supuesto en que la madre opte por la cesión del disfrute, o cuando por no recaer en la madre un derecho a la interrupción de su actividad profesional con la consiguiente prestación en término análogos, deba ser el otro progenitor quien disfrute del permiso y, por ende, de la prestación.

Cierta doctrina ha considerado oportuno reconocer un derecho de titularidad indistinta a ambos progenitores, con la intención de lograr una mayor inclusión y reparto de cargas familiares, acorde a las políticas de conciliación y corresponsabilidad de los dos progenitores (Rodríguez, 2008: 148 y 149). No obstante, la búsqueda de una mayor corresponsabilidad debiera focalizarse en una reformulación de aquel permiso donde el bien jurídico no resulte exclusivo de una de las partes, como sucede con el permiso de paternidad, y lograr a través de este que el padre asuma un papel más destacado en los cuidados del hijo (Rodríguez, 2015: 53).

Esta titularidad materna se extiende a su vez a la prestación por maternidad, si bien, el tenor del texto recogido en los arts. 3 RD 295/2009 y 178.1 LGSS muestra una apariencia de neutralidad al reconocer el derecho a las personas que disfruten del permiso de suspensión "cualquiera que sea su sexo». En ese sentido, se mantiene una posición independiente respecto a la prestación a disfrutar por el padre y la madre, en cuanto al abono del subsidio se refiere. Ahora bien, cuando de la prestación por parto se refiere, el art. 9.4 RD 295/2009 desenmascara el rol que de la madre arrastra el legislador y que "parece partir de la asunción femenina preferente de las tareas familiares", haciendo del disfrute «del otro progenitor» un derecho derivado del de la madre (Ballester, 2013: 99 y ss.).

Para que la madre, titular originaria del derecho, pueda ceder el disfrute al otro progenitor deberán concurrir una serie de requisitos y sólo entonces podrá éste disfrutar de una parte determinada e ininterrumpida del período de suspensión, que podrá ejercitarse tanto de forma simultánea como sucesiva con el de la madre. En primer lugar, establece el precepto legal que ambos progenitores deben encontrarse trabajando, esto es así ya que en el caso de que la madre no trabaje, entiende el Tribunal Constitucional (en adelante, TC) que «nadie puede ceder a otro un derecho que no tienes ${ }^{3}$, puesto que en tanto no hay un derecho originario, no hay nada que se pueda ceder ${ }^{4}$. El texto normativo entiende por «trabajan» la actividad sometida al art. 1.1 ET y art. 8 EBEP. Cuando de las trabajadoras por cuenta propia se trata, sólo podrá cederse parte del derecho cuando la mujer ostente el derecho originario por encontrarse inserta en el Ré-

\footnotetext{
3 STC 152/2011, de 29 de septiembre.

4 STC 78/2011, de 6 de junio y 75/2011, de 19 de mayo.
} 
gimen Especial de los Trabajadores Autónomos ${ }^{5}$ (en adelante, RETA) u ostente dentro de su cobertura específica de la mutualidad de previsión social un permiso equiparable al permiso por maternidad ${ }^{6}$.

En ese sentido, con motivo del asunto Roca Álvarez, consideró el TJUE que el permiso de lactancia resultaba discriminatorio respecto de la mujer, cuando éste presentaba una regulación en términos similares al permiso de maternidad actual cuando de su preferencia materna se refiere, en tanto que "puede contribuir a perpetuar un reparto tradicional de funciones entre el hombre y la mujer respecto del ejercicio de su función parentali 7 . Ello es así ya que la lactancia ya no queda circunscrita únicamente a la función de amamantar al hijo menor de nueve meses por parte de la madre trabajadora, pudiendo ser titular del permiso cualquiera de los progenitores, indiferentemente del sexo de éste. Por ello, la lactancia natural no se configura como un requisito esencial para el acceso al permiso (Maneiro, 2010: 232), y un trato diferenciado de entre los progenitores por razón de sexo, incurriría en una discriminación por tal motivo. No obstante, no extendió el Tribunal europeo esta lógica argumental al permiso de maternidad, quizás por su anclaje a una normativa de prevención de riesgos de exclusivo carácter femenino (Ballester, 2013: 104). Tampoco habrá apreciado el Tribunal Constitucional tal discriminación dentro de la prestación de maternidad.

En igual sentido, la doctrina jurisprudencial ha determinado la ausencia de discriminación para con el otro progenitor y su imposibilidad de disfrute de este derecho cuando la madre no se encuentre trabajando, ya que el disfrute del otro progenitor como derecho derivativo queda supeditado a la concurrencia de su condición de asalariada o a supuestos o de fallecimiento o ausencia, recayendo su justificación en la protección de la condición biológica de la mujer ${ }^{8}$.

Ello encuentra su sentido respecto a la preservación de los bienes jurídicos en juego, ya que de no trabajar alguna de las partes, el progenitor que no trabaje

5 Respecto al caso de trabajadoras por cuenta propia, quedan fuera de cobertura aquellas cesiones enmarcadas en un cambio estratégico por el que la madre en fechas previas al alumbramiento abandona la cobertura con la Mutualidad y se inserta en el RETA, no constando que se haya ejercido actividad económica real derivada de su nueva condición. Cuando de un modo artificioso la madre se convierte en beneficiaria del permiso de maternidad y para poder así ceder al otro progenitor los meses considerados oportunos, será éste un supuesto de fraude de ley y no dará lugar a la cesión lícita.

${ }^{6}$ En relación a la cuantía mínima de las prestaciones a cubrir por estas mutualidades: «Las prestaciones que se otorguen por las mutualidades en su condición de alternativas al citado régimen especial, cuando adopten la forma de renta, habrán de alcanzar en el momento de producirse cualquiera de las contingencias cubiertas a que se refiere el apartado anterior, un importe no inferior al 60 por ciento de la cuantía minima inicial que para la respectiva clase de pensión rija en el sistema de la Seguridad Social, (Dispoción adicional decimonovena de la LGSS).

7 STJUE de 30 de septiembre de 2010, asunto C-104/09 Roca Álvarez.

8 STJUE de 19 de septiembre de 2013, asunto C-5/12 Marc Betriu; y en el marco nacional, entre muchas otra, véase la STSJ de las Islas Canarias núm. 69/2016, de 1 de febrero (rec. 338/2015). 
podría atender a los cuidados del hijo. Cuando alguno de los trabajadores trabaje pero bajo régimen funcionarial o por cuenta propia ${ }^{9}$, se entiende que siempre que la otra parte pueda disfrutar de un derecho de contenido equivalente, será susceptible de cesión (Fernández, 2013: 45-49).

En referencia a la no concesión del permiso de lactancia a uno de los progenitores cuando el otro no se encuentre trabajando, según lo establecido en el art. 48.f) EBEP, no ha apreciado el TC que concurra discriminación como consecuencia de un "tratamiento peyorativo fundado en el sexo", ya que resulta indiferente quién de los dos no cumpla el requisito de encontrarse empleado ${ }^{10}$. En lo que resulta extrapolable al permiso de maternidad, no habrá discriminación cuando la medida busque la preservación de un bien jurídico, indiferentemente del sexo de los progenitores.

Del mismo modo, en el permiso de maternidad la cesión viene a garantizar que las madres que tienen la condición de trabajadoras por cuenta ajena puedan cuidar de sus hijos a la par que conservan su empleo, ya que el otro progenitor sobre el que concurra la condición de asalariado podrá disfrutar de esta suspensión en lugar de la madre.

Sin embargo, esa lógica decaería respecto del período inmediatamente posterior al parto, ya que el período dirigido a la restitución física de la madre sólo por ella puede ser disfrutado. De esa manera, se entiende que el segundo requisito sea el no compromiso por la cesión del período de descanso de 6 semanas posterior al parto.

Como tercer requisito, la cesión y consecuente comunicación al empresario habrá de formularse al inicio del período, sin que quepan posibles modificaciones posteriores. Se trata con ello de mantener un cierto margen de maniobra para la organización de la empresa, no obstante, la imposibilidad de posteriores cesiones parece contradecir la intención del legislador cuando sí admite la revocación posterior de la cesión (Fernández, 2013: 52). Esta rígida restricción de realizar una cesión a fecha posterior puede desembocar en una desatención del debido cuidad del menor, por ello, se presenta recomendable transferir inicialmente parte del derecho y, en su caso, revocarlo posteriormente (Rodríguez, 2015: 63).

El segundo supuesto en el que otro progenitor podrá disfrutar del permiso de maternidad será en los casos en los que la madre haya fallecido, independientemente de que ésta realizará algún trabajo o no, la otra parte disfrutará del período que reste por disfrutar tras el parto, no pudiéndose descontar el tiempo de suspensión que la madre hubiese disfrutado previo al parto. Con ello, se trata de asegurar los primeros cuidados necesitados por el recién nacido.

\footnotetext{
9 Art. 2.4 RD 295/2009.

10 Auto del TC núm. 14/2016, de 19 de enero.
} 
En tercer lugar, disfrutará el otro progenitor de este derecho cuando la madre no tenga derecho a la suspensión de su actividad profesional para el percibo de una prestación equivalente. A través de este precepto, la normativa busca garantizar que el bien jurídico que representa el cuidado del recién nacido no se vea mermado por la carencia de rentas durante el descanso por maternidad (Fernández, 2013: 55). En caso contrario, de no poder el otro progenitor disfrutar de este derecho podría dar lugar a que una mujer trabajadora por cuenta propia, sobre la que no concurra el permiso ni prestación específico, tuviese que suspender o cesar su actividad profesional para soportar ella sola la carga del nacimiento de su hijo sin poder contar con la ayuda del otro progenitor.

Ahora bien, vista la norma estatutaria, el art. 3.4 del RD 295/2009 establece que para que el otro progenitor pueda disfrutar de la suspensión y la consiguiente prestación, la madre trabajadora por cuenta propia debe estar incorporada a la mutualidad de previsión social establecida por el correspondiente colegio profesional, y que no tuviera derecho a prestaciones por no estar prevista la protección por maternidad en la correspondiente mutualidad. Es decir, en aquellos supuestos es lo que la madre ya ostente el derecho a un permiso por maternidad, ya sea dentro del Régimen Especial ${ }^{11}$ o de la Mutualidad correspondiente, e indiferentemente de la duración o cuantía con la que se cubra la contingencia, no cabrá que el otro progenitor con condición de asalariado disfrute del permiso de maternidad ${ }^{12}$.

En esa línea, establece la normativa que para poder el otro progenitor disfrutar del derecho no deberá la madre tener prevista una prestación equiparable. No modificará las consecuencias el carácter de indemnización a tanto alzado de las cuantías prestacionales, ni tampoco el montante económico de las mismas ${ }^{13}$. Tampoco podrá el otro progenitor disfrutar del período de suspensión, cuando la ausencia de cobertura análoga venga provocada por un acto voluntario de la madre al no optar deliberadamente por dicho aseguramiento cuando era posible $^{14}$. En ese sentido, sólo los casos en los que no medie voluntariedad de la madre para contratar la cobertura por maternidad, tal es el caso en el que no se reúne la carencia exigida para la concesión de la prestación a cargo de la mutua, podrá el otro progenitor disfrutar del derecho ${ }^{15}$.

$\mathrm{Al}$ respecto, no considero apropiado al bien jurídico a proteger la excepción del disfrute por el otro progenitor cuando éste cumpla los requisitos pero la mujer trabajadora no pueda disfrutar de un cese de su actividad profesional por

11 STSJ de Cataluña núm. 9493/2008, de 17 de septiembre (rec. 4681/2008).

12 STSJ de Asturias núm. 238/2016, de 9 de febrero [rec. 2637/2015]; STSJ de las Islas Canarias núm. 69/2016, de 1 de febrero (rec. 338/2015).

13 STSJ de Castilla y León, Burgos núm. 223/2015, de 8 de abril (rec. 161/2015).

14 STSJ de Castilla y León, Burgos núm. 586/2016, de 10 de noviembre (rec. 548/2016).

15 STSJ de Asturias núm. 1986/2015, de 23 de octubre (rec. 1728/2015). 
consistir su cobertura de la contingencia en una suma indemnizatoria a tanto alzado sin necesidad de causar baja. Dentro de la necesaria atención y cuidados del menor que se buscan proteger a través de este permiso, y la compensación de la merma de rentas a la que se dirige la prestación respectiva, no entiendo cumplidos dichos objetivos cuando la madre obtiene una indemnización a tanto alzado (a menudo no de gran cuantía) sin causar baja, ya que la realidad genera que sea ella quien tenga que atender finalmente al hijo, en tanto el padre no puede hacer uso de ese descanso, con la consiguiente limitación sobre su actividad profesional. En ese sentido, lejos queda la corresponsabilidad de ambas partes en las cargas derivadas del nacimiento del hijo.

En ese sentido, encuentro admisible la doctrina por la que cuando el artículo 3.4 RD 295/2009 habla de "prestaciones de maternidad en el sistema de previsión social,, no puedan entenderse inclusas en tal concepto sino las prestaciones que la Seguridad Social dispensa o los períodos de descanso equiparables, debiendo quedar excluidas las indemnizaciones a tanto alzado previstas por las mutualidades. De otro modo, y según lo previsto por el art. 8 LOI, se genera sobre la mujer embarazada una discriminación por su condición de trabajadora por cuenta propia, al sufrir ésta una consecuencia desfavorable porque el otro progenitor no puede acceder al subsidio (Cabeza, 2010: 351 y ss.).

\subsubsection{Maternidad por adopción o acogimiento}

En los supuestos de adopción o acogimiento ${ }^{16}$ la suspensión y consiguiente prestación se inician una vez se formalice la resolución judicial o la decisión administrativa que origina el derecho (art. 48.5 ET), con la excepción del posible disfrute anticipado cuando se requiera un desplazamiento previo al lugar de origen de la adopción internacional.

Como supuesto materialmente distinto de la maternidad biológica, ya que no concurre ningún evento fisiológico que genere sobre los adoptantes o acogedores una diferencia, no se genera conflictividad derivada de una posible discriminación por razón de sexo entre las parte actuantes y sus derechos. En ese sentido, la normativa no hace un trato diferenciado por sexo sino que se refiere a los progenitores indistintamente de su género, sin que se genere un derecho preferente de titularidad hacía ninguna de las partes sino un reconocimiento de cotitularidad indistinta.

Los términos de comparación donde puede apreciarse una discriminación nos lo encontramos cuando el término comparativo se circunscribe a las condi-

16 Se incluye el acogimiento familiar «tanto preadoptivo como permanente o simple, de conformidad con el Código Civil o las leyes civiles de las comunidades autónomas que lo regulen, siempre que, en este último caso, su duración no sea inferior a un año, y aunque dichos acogimientos sean provisionales» (art. 2.1 RD 295/2009). 
ciones reconocidas a los progenitores adoptantes respecto de los derechos de los progenitores biológicos, ya que las situaciones de adopción y acogimiento deben generar sobre el adoptante los mismos derechos y obligaciones que posee un padre o madre respecto de su hijo biológico, sin que pueda prevalecer diferencia por motivo de filiación ${ }^{17}$. El propósito de un permiso de maternidad para una madre o padre adoptiva es permitir que se permanezca en casa para cuidar a su hijo, y en ese sentido, se está en una situación similar a la de los progenitores biológicos ${ }^{18}$.

Ejemplo de lo anterior, se planteó en sede judicial la posible discriminación con motivo de la diferencia de trato, en detrimento del padre biológico, entre el supuesto de parto y el supuesto de adopción (o acogimiento). A diferencia de lo previsto para el caso de adopción o acogimiento, donde el padre adoptante es titular del permiso y puede disfrutar de las 16 semanas que le reconoce el permiso de maternidad indiferentemente de que el otro progenitor trabaje o no, como ya se ha visto, el padre biológico no puede disfrutar del descanso cuando la madre no puede cederle un permiso de maternidad del que no es titular por no encontrarse trabajando ${ }^{19}$.

No obstante, no se consideró contrario a la constitución el tratamiento desigual que en ambos supuestos confluye, dado que el elemento diferenciador del permiso de maternidad por parto y por adopción o acogimiento, y los diferentes bienes jurídicos protegidos en cada caso ${ }^{20}$ generan que la diferencia de trato resulte fundamentada en una justificación objetiva y razonable.

\subsubsection{Maternidad subrogada}

Como tercer supuesto de reconocimiento de la prestación de maternidad se presenta la controvertida maternidad subrogada o gestación por subrogación. La maternidad por sustitución irrumpe como un fenómeno social con diferente grado de encaje dentro de los distintos ordenamientos jurídicos comparados, haciendo tambalear conceptos como el orden público internacional de cada estado e intereses confluyentes como el interés del menor, así como dilemas de índole ética y política como la protección de la mujer respecto a la mercantilización de su cuerpo y su organismo reproductor. Todos ellos intereses de difícil delimitación y que, en definitiva, penden de la opción política que cada legislador nacional entienda apropiada a los valores imperantes en su ordenamiento jurídico.

17 Art. 8 del Convenio europeo en materia de adopción de menores y art. 39.2 CE.

18 Sentencia del Tribunal Europeo de Derechos Humanos, caso Topic-Rosenberg contra Croacia, de 14 de noviembre de 2013.

19 STC 152/2011, de 29 de septiembre.

20 Siguiendo la doctrina del principio de igualdad de la doctrina del Tribunal Europeo de Derechos Humanos, hecha nuestra por medio de la STC núm. 22/1981, de 2 de julio, véase la STC 152/2011, de 29 de septiembre. 
Una mirada conceptual nos lleva a hablar de maternidad subrogada como la "práctica en la que una mujer se queda embarazada con la intención de ceder el niño a otra persona al nacern (Brunet, 2012). Respecto a las partes identificables, por un lado estará la madre biológica, que hará de madre gestante y podrá aportar o no los gametos del menor que alumbrará, y por otro, los comitentes que podrán ser o una pareja heterosexual, del mismo sexo, o un solo comitente. Ambas partes negociarán a través de un contrato, ya sea oneroso o lucrativo (depende en qué lugar se realice el acuerdo sólo tendrán carácter legal los primeros o ambos), la gestación del embrión del que una vez nacido, la madre biológica renunciará a los derechos y deberes propios de la maternidad para pasar a reconocerse la filiación a cargo de los comitentes.

Entre los motivos para recurrir a esta técnica de reproducción asistida la casuística presente varias causas que, a su vez, se correlacionan con el perfil de los comitentes y el aporte genético o no de éstos para la conformación del embrión. Por un lado, el primer supuesto prototípico desvela el caso de la pareja heterosexual en la que debido a una disfunción de la capacidad reproductiva de la mujer, se opta por recurrir a esta práctica, de modo que resulta usual que en estos supuestos el padre aporte material genético y, posiblemente, la madre también ${ }^{21}$. En tal caso, la madre gestante únicamente no aporta material genético, no obstante, puede darse el caso de que el padre comitente sea el único que aporte material genético, siendo los gametos provenientes de la madre gestante o de una donación.

Otro de los supuestos prototípico será el de la pareja del mismo sexo, normalmente varones, que acuden a esta práctica como única salida ante su incapacidad reproductora. En estos casos, uno de los dos varones será el que aporte el esperma para la fecundación y la madre gestante o una donante, el óvulo. Puede darse el caso de que ambas partes sean de sexo femenino, sin embargo, en el caso de que una de ellas pudiera gestar el embrión, parece entendible el recurso a la inseminación artificial como vía preferente a la gestación por sustitución.

El tercero de los supuestos se corresponderá con el caso de una familia monoparental, en la que el varón acude a esta práctica aportando el esperma y, por lo tanto, manteniendo la paternidad biológica. Como se apuntaba en el caso previo, raro sería el caso de que una mujer recurriese individualmente a esta práctica para formar una familia monoparental, a excepción de que pudiese

${ }^{21}$ El caso de Portugal, donde la gestación por subrogación viene admitida excepcionalmente en supuestos de "ausência de útero, de lesão ou de doença deste órgão que impeça de forma absoluta e definitiva a gravidez da mulher ou em situaçôes clínicas que o justifiquem» (art. 8.2 Lei n.o 25/2016, de 22 de agosto, Regula o acesso à gestaçáo de substituição). Normativa recientemente desarrollada a través del Decreto Regulamentar n.o 6/2017, de 30 de julho. Disponible en (última visita el 27/11/2017):

https://dre.pt/application/conteudo/107785481 
aportar material genético, de modo que aportase ella el gameto femenino y el esperma fuese obtenido de un donante.

Visto ello, puede el lector vislumbrar el foco de conflictividad que se genera respecto a la materia objeto de análisis. El hecho de que en algunos países esta práctica esté legalizada, en ocasiones incluso incentivada, genera que familias hayan recurrido internacionalmente a una práctica que nacionalmente tienen vetada para, posteriormente, retornar al país de origen con un recién nacido fruto de un contrato que su ordenamiento jurídico no prevé o llegar a prohibir. En este marco, diversas son las suspicacias generadas respecto a la situación de los comitentes y los menores pero, en lo que a efectos de prestaciones públicas compete, la problemática deviene cuando estas madres y padres pretenden que les sea reconocida la titularidad de permisos como el de maternidad y lactancia, con las consiguientes prestaciones. Consiguientemente, la disyuntiva aflora incertidumbres respecto a posibles efectos de discriminación por razón de sexo o por motivo de filiación ante una eventual denegación de las prestaciones.

De esta manera, como paso previo deviene necesario analizar las recientes sentencias emanadas del TJUE sobre maternidad subrogada para, posteriormente, tratar de entender los últimos pronunciamientos del Tribunal Supremo y la consiguiente corriente jurisprudencial.

\section{a) Una lectura según la jurisprudencia más reciente del TJUE}

Dos son las sentencias que centran el análisis: la SSTJUE de 18 de marzo de 2014, asunto 363/12, C. D. contra S. T.; y asunto C-167/12, Z. contra A. Government department, The Board of management of a community school.

La primera de las sentencias recoge el supuesto de una pareja heterosexual (Reino Unido) que acude a un país tercero para obtener, a través de un contrato de gestación por sustitución, un hijo para el que el padre facilita el esperma y la madre gestante el óvulo. Una vez retornan al RU, la madre comitente solicita que le sea reconocida la prestación por maternidad, y ante la negativa por no encajar en el concepto de madre biológica, aduce una posible discriminación por razón del sexo y/o del embarazo y la maternidad. Como elemento particular del caso, cabe mencionar el hecho de que la madre ha podido amamantar al recién nacido durante un período de tres meses.

Dicho ello, se plantea ante el TJUE si el supuesto de una madre subrogante que tiene un hijo en virtud de un convenio de gestación por sustitución entra dentro del marco tuitivo de la Directiva 92/85/CEE ${ }^{22}$ que viene a proteger a la

22 DIRECTIVA 92/85/CEE del Consejo, de 19 de octubre de 1992, relativa a la aplicación de medidas para promover la mejora de la seguridad y de la salud en el trabajo de la trabajadora embarazada, que haya dado a luz o en período de lactancia. 
mujer que haya dado a luz o se encuentre en período de lactancia y si, también en aplicación de esta normativa, y siendo que la madre comitente ha podido amamantar y así lo ha hecho con el recién nacido, le correspondería o no una prestación por maternidad. Igualmente, se pregunta el juzgado británico si el no reconocimiento de la prestación por maternidad a la madre comitente no genera una infracción del art. 14 de la Directiva 2006/54/CEE ${ }^{23}$ por concurrir entonces una discriminación, ya sea directa o indirecta, por razón de sexo.

El TJUE determina que con fundamento en la Directiva 92/85, se otorga protección a la mujer que haya estado embarazada y haya dado a luz a un niño, por ello, en los casos de madres subrogantes no nos encontraremos dentro del ámbito objetivo del art. 8 de la Directiva, ya que estas madres no han estado encintas ni tampoco han alumbrado al niño, sin que ello se altere porque la madre comitente haya amamantado o no al mismo. Por ello, sostendrá el Tribunal de Justicia, los "Estados miembros no están obligados en virtud de ese artículo a conferir a esa trabajadora un permiso de maternidad", es decir, queda al arbitrio de cada Estado la aplicación de disposiciones más favorables como la extensión de la prestación por maternidad a estos supuestos de reproducción artificial, si bien, no podrá inferirse una obligación en tal sentido de la normativa europea, ni siquiera en los casos en los que la madre "puede amamantar a ese niño tras su nacimiento o lo amamanta efectivamente».

En lo referido a la posible discriminación por razón de sexo de la madre subrogante, no aprecia el Tribunal europeo una discriminación ni directa ni indirecta en tal sentido. Ello es así, se sostendrá, ya que no se recoge en la normativa nacional un permiso equivalente o comparable al de maternidad y que sea reconocido para los padres, por lo que la negativa no viene afecta por una cuestión de sexo. $\mathrm{Ni}$, en lo que a la discriminación indirecta se refiere, queda acreditado «que la denegación del permiso en cuestión perjudique especialmente a las trabajadoras en comparación con los trabajadores».

En definitiva, dado que el supuesto de la maternidad por sustitución no encaja como supuesto de obligada cobertura prestacional acorde a la Directiva, difícilmente puede apreciarse un trato menos favorable de la madre subrogante ligado al disfrute de un permiso de maternidad en el sentido de la Directiva $92 / 85$, y decae la argumentación de una hipotética discriminación por razón de sexo.

La segunda de las sentencias a las que se hace mención, de 18 de marzo de 2014, asunto C-167/12, el supuesto de hecho muestra un caso de una pareja irlandesa que, ante la afección de la madre consistente en la falta de útero, recu-

23 DIRECTIVA 2006/54/CE del Parlamento Europeo y del Consejo de 5 de julio de 2006 relativa a la aplicación del principio de igualdad de oportunidades e igualdad de trato entre hombres y mujeres en asuntos de empleo y ocupación (refundición). 
rren a la gestación por subrogación. La afección de la madre no suponía que ésta fuese infértil pero sí su imposibilidad para gestar, de modo que ambos comitentes ofrecieron los gametos necesarios para la conformación del embrión que la madre gestante daría a luz, convirtiéndose ambos comitentes en madre y padre genéticos. Una vez retornados a Irlanda con el recién nacido, la madre ve denegada la petición tanto del permiso de maternidad como de adopción, al no reunir los requisitos para el acceso a las mismas. Por ello, considerando la demandante que había sido objeto de trato discriminatorio por motivos de sexo, estatuto familiar y discapacidad, el Equality Tribunal de Irlanda plantea varias sendas cuestiones prejudiciales a fin de dilucidar tales extremos en concordancia con la normativa europea.

$\mathrm{Al}$ igual que en la anterior sentencia, dentro del ámbito subjetivo de la Directiva 2006/54/CEE se plantea si no existe una discriminación por motivo de sexo cuando a una mujer que ha obtenido a su hijo a través de la técnica de la gestación subrogada, se le deniega el permiso y la prestación por maternidad y/o adopción. Junto a ello, como elemento característico del caso, se pregunta el Tribunal irlandés si no puede, a su vez, incurrirse en una discriminación por discapacidad según lo previsto en la Directiva 2000/78, cuando a una mujer con una discapacidad que afecta a su organismo reproductor y cuyo hijo genético ha nacido a través de la maternidad por sustitución, se le deniega el acceso a un permiso retribuido equiparable al de maternidad y/o adopción.

Respecto al primero de los extremos, al igual que se mantiene en la primera de las sentencias, no aprecia el TJUE que concurra una discriminación por razón de sexo en tanto un hombre que recurra a la práctica de la gestación subrogada recibiría el mismo trato que la mujer subrogante en un situación comparable, y no tendría derecho al disfrute de un permiso retribuido equiparable al de la prestación por maternidad o paternidad. Tampoco se considera que exista una discriminación indirecta por razón de sexo, entendida esta como la derivada de la aplicación de una medida nacional, que aunque formulada de manera neutra, perjudica de hecho a un número mucho mayor de trabajadores de un sexo que del otro. $\mathrm{Y}$ en este sentido, no puede mantenerse que una medida como la del litigio se perjudique en mayor medida a las trabajadoras.

Por todo ello, la denegación de un permiso retribuido equivalente a un permiso de maternidad a las madres subrogantes no constituye una discriminación, ni directa ni indirecta, en el sentido de la Directiva 2006/54, y concretamente de sus artículos 4 y 14.

En lo concerniente a una posible discriminación derivada de la negativa al permiso de adopción, aclara el Tribunal que lo concerniente a la atribución de un permiso por adopción no está comprendida en esta Directiva y queda ligado a la normativa nacional de cada Estado miembro. 
En último lugar, responde negativamente a la cuestión prejudicial acerca de la posible discriminación por motivo de discapacidad, ya que, sostendrá el Tribunal, la afección de la mujer que le impide gestar a su hijo no "ha originado por si misma la imposibilidad de que la interesada ejecute su trabajo o haya constituido una dificultad en el ejercicio de su actividad profesional" y no se considera que dicha incapacidad constituya en principio «un impedimento para que la madre subrogante acceda a un empleo, lo ejerza o progrese en éli. En ese sentido, no se considera que la afección encaje dentro del término «discapacidad» de la Directiva 2000/78 y, por ende, no puede mantenerse que concurra una discriminación por motivo de ésta.

Vistas ambas sentencias, la primera conclusión que se arroja es la inclusión dentro del ámbito subjetivo de la Directiva 92/85 de los casos en los que la madre se encuentre embarazada y dé a luz, quedando fuera los casos que no se traten de maternidad biológica como resulta con la gestación por subrogación, con indiferencia de que posteriormente la madre haya podido o no amamantar al recién nacido.

En esa línea, la denegación de un permiso retribuido equiparable al de la prestación por maternidad no constituye discriminación directa en tanto el hombre tampoco recibiría un trato diferente en un supuesto equiparable.

Sin embargo, vuelve a aflorar sobre el Tribunal europeo la perpetuación de roles discriminatorios cuando hace suya la doctrina jurisprudencial previa de la doble intencionalidad del permiso por maternidad, confiriéndole un carácter protector de la especial relación que une a la madre con los recién nacidos en los primeros meses de vida de estos (Rodríguez, 2017: 111). En ese sentido, no parece ser congruente la no inclusión dentro del ámbito subjetivo de la Directiva 92/85 del supuesto en el que la madre sí puede amamantar naturalmente a su hijo, ya que se coloca a la trabajadora en una situación desfavorable respecto de otros trabajadores varones (Rodríguez Rodríguez, 2017: 111). De igual modo, ello genera un trato desfavorable sobre los menores que han sido concebidos como consecuencia de un convenio de subrogación respecto de los que no lo han sido.

Asimismo, en lo referido a los principios de igualdad entre hombre y mujeres y su capacidad para acceder al empleo, el TJUE no ha tenido en cuenta que el permiso que se solicita es un permiso de titularidad materna y que su protección sólo puede otorgarse a la mujer embarazada, de modo que un trato desfavorable como el recaído sobre la mujer que sí puede amamantar a su hijo puede generar una discriminación por razón de sexo en este sentido (Rodríguez, 2017: 111).

Dicho ello, como conclusión principal de ambas sentencias, cabe extraer que la maternidad subrogada no encuentra cobijo dentro del ordenamiento co- 
munitario, de modo que los Estados miembros no vienen obligados a reconocerla como situación que origine el derecho a las prestaciones por maternidad (Gorelli, 2017: 10-12). Ahora bien, queda a la voluntad legislativa de cada Estado el reconocer unos derechos más favorables en este sentido.

\section{b) Una lectura según la jurisprudencia española más reciente}

Como ha quedado visto, el ordenamiento jurídico español otorga cobertura retributiva a los permisos de maternidad biológica, adopción y acogimiento (arts. 48.4 y 177 LGSS), pero nada dice de la extensión a la maternidad subrogada. No obstante, como fenómeno presente en nuestra sociedad, también ha suscitado a nivel interno la conflictividad jurídica que a nivel europeo se mostraba, de modo que el legislador español ha optado por reconocer la nulidad de pleno derecho de esta práctica, si bien, reconociendo la salvedad de la acción de reclamación de paternidad respecto del padre biológico (art. 10 Ley 14/2006, de 26 de mayo, sobre técnicas de reproducción humana asistida). Esta práctica puede llegar a ser considerada, a su vez, como delito en los arts. 220 y $221 \mathrm{CP}$.

Desde la jurisprudencia civil la doctrina unificada ha entendido que estas prácticas resultan vulneradoras del orden público internacional español y no pueden generar efectos de filiación. En este sentido, se entiende que nuestro ordenamiento prevé otras fórmulas como la adopción para garantizar intereses en juego como el interés superior del menor y su efectiva integración en el núcleo familiar "de facto», sin tener para ello que transgredir el orden público ${ }^{24}$. Ahora bien, como adelanto para el lector, la sala de lo social del Alto Tribunal parece desligarse de la doctrina de la sala de lo civil y abre un camino diverso dentro de los efectos que en el ámbito laboral pueden derivarse de esta práctica.

Dentro de las situaciones protegidas por el art. 2.2 del RD 295/2009, y ahora se presenta la problemática interpretativa, se prevé que «se considerarán juridicamente equiparables a la adopción y al acogimiento preadoptivo, permanente o simple, aquellas instituciones juridicas declaradas por resoluciones judiciales o administrativas extranjeras, cuya finalidad y efectos juridicos sean los previstos para la adopción y el acogimiento preadoptivo, permanente o simple, cuya duración no sea inferior a un año, cualquiera que sea su denominación». En consecuencia, se abre el debate acerca de la posibilidad de encajar dentro de este precepto una práctica extranjera como la gestación por subrogación.

De la negativa inicial del INSS al reconocimiento del subsidio de maternidad para los casos de gestación subrogada, se inició un vaivén jurisprudencial en ambos sentidos, si bien con una preponderancia estimatoria del reconocimiento de la prestación (Aragón, 2017: 9 y ss.). Así, se llega a la STS de 25 de octubre

24 STS de 6 de febrero de 2014 (rec. 245/2012). 
de 2016 (rec. 3818/2015) ${ }^{25}$ en la que se resuelve acerca del derecho a la prestación de maternidad de un padre de dos hijas recién nacidas a través del recurso a la gestión subrogada en el extranjero (Nueva Delhi), en las que él aporta el material genético para ello y por ende se convierte en padre biológico y también registral.

El Alto Tribunal realiza en la sentencia una recapitulación de la doctrina jurisprudencial del TJUE, del TEDH ${ }^{26}$, y de la Sala de lo Civil del propio Tribunal Supremo, para redefinir su propia postura jurisprudencial. En ella, se reconoce la ausencia de referencia expresa a la maternidad subrogada dentro del marco jurídico de las prestaciones de maternidad. No se niega el carácter de nulidad de pleno derecho del contrato de gestación por sustitución, ahora bien, dirá la sentencia, la Ley 14/2006, de 26 de mayo, sobre técnicas de reproducción humana asistida no alude al régimen prestacional en el ámbito de la Seguridad Social ni responde a la lógica de este. Como afirma la sentencia, la nulidad no elimina la situación de necesidad surgida por el nacimiento del menor y su inserción en un determinado núcleo familiar.

Ciertamente, la prestación de maternidad en España busca la recuperación física del estado de salud de la madre, así como garantizar los necesarios cuidados que el recién nacido precisa y, en ello, nuestro ordenamiento no constrińe el permiso retribuido a los casos de parto sino que admite supuestos como el de adopción o acogimiento. Dentro de estos últimos, el art. 2.2 RD 295/2009 reconoce una equiparación a estas situaciones de las instituciones jurídicas declaradas por resoluciones judiciales o administrativas extranjeras, cuya finalidad y efectos jurídicos sean los previstos para la adopción y el acogimiento. Con ello, entiende el TS que puede interpretarse análogamente la maternidad subrogada con los casos de adopción, máxime cuando el padre resulta ser el padre biológico de las recién nacidas, como es el caso enjuiciado.

No tendría sentido, a juicio de la sala, que nuestro ordenamiento reconozca en el art. 3.2 RD 295/2009 el disfrute del otro progenitor cuando la ma-

25 Previamente, la STS de 19 de octubre de 2016 [rec. 1650/2015], somete a casación la STJUE de 18 de marzo de 2014, asunto 363/12, sin embargo, el TS no aprecia que concurra contradicción entre ambas resoluciones. No obstante, el alto Tribunal asume la doctrina jurisprudencial por la que únicamente entrarían dentro del Derecho de la Unión los casos de maternidad biológica, sin que concurra discriminación por razón de sexo al excluir de la pensión retributiva a las madres subrogantes.

26 SSTEDH de 26 de junio de 2014, caso Menneson v. Francia (demanda 65192/11) y de 27 de enero de 2015, caso Paradiso v. Campanelli (demanda 25358/12), ambas en relación a la viabilidad y validez de la inscripción registral de unos hijos fruto de un contrato de gestación por subrogación. En ellas, el Tribunal considera, si existe convivencia familiar entre los padres subrogados y los menores, ha de protegerse en beneficio de los segundos, máxime cuando uno de los padres resulta biológico. De otro modo, se estaría conculcando el art. 8 del Convenio Europeo de Derechos Humanos, respecto al respeto a la vida privada, incluida su filiación, del menor. 
dre biológica fallezca o cuando no tenga derecho al cese de su actividad profesional con derecho a prestaciones equiparables y, sin embargo, se niegue el disfrute del permiso de maternidad al padre en estos casos, en los que igualmente pervive la misma situación de necesidad del menor. Por ello, se entiende como adecuada una interpretación analógica respecto de la maternidad subrogada y hacer una interpretación en el sentido más favorable a los «objetivos de protección del menor, con independencia de su filiación, y de conciliación de vida familiar y laboral, ${ }^{27}$.

Lo controvertido del caso queda manifiesto con los tres votos particulares formulados a la sentencia. Con ello, no sólo se alude a la falta de contradicción no reconocida, lo cual es esgrimido por el voto particular primero, sino que como se recoge en el segundo de los votos particulares, no puede ni reconocerse efectos jurídicos tales de un contrato afecto de nulidad (en fraude de ley para quienes formulan el tercer voto particular), ni puede erigirse la Sala en creadora de derecho ante un caso como el presente, de modo que con el fin de proteger el interés superior del menor pueda el TS contravenir la normativa vigente. Del mismo modo, no cabe admitir una interpretación analógica en materia de Seguridad Social e introducir así el supuesto de maternidad subrogada dentro de los casos cubiertos por las prestaciones de maternidad.

De lo dicho, se comparte desde esta parte la posición del segundo voto particular en tanto no puede considerarse que exista un vacío legislativo que requiera de una interpretación analógica, realmente, "no hay un problema de anomia normativa, sino antinomia jurídica» (Aragón, 2017: 18), ni tampoco concurren dos hechos razonablemente similares como para optar por la solución analógica que hace la sentencia (Gorelli, 2017: 19). Si el legislador no ha considerado a bien incluir dentro del derecho a la prestación por maternidad la gestión por subrogación, independientemente de la opinión favorable que se pueda tener sobre la normativización de esta práctica, no puede contravenirse esta política legislativa en sede judicial.

Igualmente, no considero que por mor de garantizar el interés superior del menor pueda justificarse tal interpretación analógica, ya que dicho interés quedaría plenamente garantizado mediante el reconocimiento al padre de su paternidad biológica y la adopción por su pareja (cuando no se trate de familias monoparentales), o en el caso de que la prestación fuese solicitada por una madre subrogante, a través de la vía de adopción.

Por todo ello, en tanto no se modifique la doctrina unificada por el TS, los juzgados de lo social seguirán entendiendo que los comitentes de un contrato de sustitución resultan titulares del derecho a la maternidad del art. 177 LGSS.

\footnotetext{
27 En este sentido, se acerca el TS a la doctrina del TEDH y su interpretación del art. 8 para con los casos de maternidad subrogada.
} 
En ese sentido, se han hecho eco de dicha doctrina las SSTSJ de Islas Baleares, de 30 de enero de 2017 (rec. 398/2016), de País Vasco, de 16 de mayo de 2017 (rec. 554/2017) y de Castilla y León, de 20 de julio de 2017 (rec. 624/2017).

No obstante, esta incongruencia de posturas entre las diferentes disciplinas, desmarcándose la Sala cuarta de la jurisprudencia de lo civil y lo penal, genera situaciones antagónicas como que mientras se siguen unas diligencias penales derivadas de delito a una pareja como consecuencia de acudir a un contrato de sustitución dentro del marco nacional, por otra, se reconoce efectos como la prestación de maternidad a aquellas personas que acuden internacionalmente a esta misma práctica. En ese sentido, sólo aquellas personas que han podido costearse las altas cifras que conlleva concertar un contrato de gestación por subrogación en el extranjero, pueden posteriormente hacer efectiva su condición de familia de facto en España y obtener derechos en consecuencia. Mientras, aquellos que no han dispuesto de medios para costearse una gestación por subrogación más allá del "made in Spain», se encuentran imputados por la supuesta comisión de un delito (Molina, 2017: 204-210).

\section{El permiso de paternidad y sus prestaciones}

Con la entrada en vigor de la LOI se introdujo la que fue considerada como la medida más innovadora para favorecer la conciliación de la vida personal, familiar y laboral de las trabajadoras y lograr con ella una mayor involucración de los varones en lo que a las cargas del recién nacido se refiere. El permiso de paternidad fue visto como la única forma eficaz de contribuir a la consecución del principio de igualdad de trato y de igualdad de oportunidades entre hombres y mujeres (Aguilera y Gil, 2010: 106-107).

\subsection{Situación protegida}

Con el fin de preservar el principio de igualdad, el permiso de paternidad se configura tomando como referente el permiso de maternidad (art. 45.1.d) ET). La suspensión por paternidad podrá derivar de un nacimiento de hijo biológico o de adopción y acogimiento, tanto preadoptivo como permanente o simple, de menores de seis ańos o de menores de edad pero mayores de seis años que tengan alguna discapacidad o que tengan especiales dificultades de inserción social o familiar. A estos efectos, se reconoce un "derecho a la suspensión del contrato por paternidad durante cuatro semanas ininterrumpidas, ampliables en los supuestos de parto, adopción, guarda con fines de adopción o acogimiento múltiples en dos días más por cada hijo a partir del segundo» (art. 48.7 ET).

En consonancia, se prevé una prestación de paternidad ante el permiso previsto en el art. 48.7 ET, o durante el período de permiso que se disfrute, en 
los mismos supuestos, de acuerdo con lo dispuesto en el artículo 49.c) EBEP (arts. 183 LGSS y 22 RD 295/2009).

En lo que al bien jurídico tutelado se refiere, desaparece en estos casos la recuperación física de la madre como consecuencia del alumbramiento, para concurrir únicamente la especial atención requerida por el menor en los primeros días tras el nacimiento.

\subsection{Titularidad}

La titularidad será originaria, sin que tenga que derivar de un derecho de la madre, como sucede en los supuestos de disfrute de las prestaciones de maternidad por el "otro progeniton». Serán titulares los trabajadores "por cuenta ajena o por cuenta propia, cualquiera que sea su sexo» (art. 23 RD 295/2009), si bien, en los casos de parto corresponderá este al «otro progenitor» y en los supuestos de adopción o acogimiento, al progenitor que resulte electo entre los interesados.

Para los casos de familias monoparentales, el disfrute de esta prestación resultará incompatible respecto del disfrute del subsidio por maternidad (art. 23.3 RD 295/2009), lo cual podría generar una situación de discriminación para estas realidades familiares, atendiendo al bien jurídico tutelado que es el cuidado del menor (Rodríguez, 2015: pág. 78).

Los trece días de los que el trabajador tenía derecho a suspender el contrato de trabajo, con fecha de 1 de enero de 2017, han sido aumentados a las cuatro semanas que preveía la Ley 9/2009, de 6 de octubre. De esa manera, el permiso tendrá una duración de veintiocho días naturales, ampliables en caso de nacimiento de hijo, adopción o acogimientos múltiples, tanto para el personal funcionariado como para el personal laboral (Gala, 2017a: 2).

En este sentido, se ha criticado la diferente duración del permiso de paternidad respecto del permiso de maternidad, con la consiguiente merma de la corresponsabilidad que ello conlleva. Tal diferencia de trato se ha entendido justificada en cuanto no concurre en esa prestación la necesidad de proteger un estado físico como el de la madre trabajadora ${ }^{28}$, no obstante, sí persiste el bien jurídico del cuidado del menor con los primeros cuidados. Por ello, se ha defendido la necesidad de acometer un reequilibrio de ambos permisos como medida positiva para lograr la efectiva corresponsabilidad (Muñoz, 2017).

Serán beneficiarios de esta prestación los trabajadores que voluntariamente lo soliciten y que acrediten estar de alta y haber cotizado por un período mínimo de cotización de 180 días, dentro de los siete ańos inmediatamente an-

28 STSJ de Navarra, de 2 de febrero de 2017 (rec. 13/2017). 
teriores a la fecha de inicio, o alternativamente, los que hubieren cotizado 360 días a lo largo de su vida laboral desde la fecha de solicitud.

No se establece aquí, al contrario que como se contempla para la prestación por maternidad, un sistema de período reducido para los menores de 26 años, a fin de incentivar el cumplimiento del requisito por aquellos jóvenes que dada su escasa carrera profesional y la tardía incorporación al mercado de trabajo, no han podido reunir esos períodos de cotización exigidos. Un trato diferenciado este que, atendiendo a la línea de equiparar la maternidad y la paternidad que subyace en esta prestación, debería haberse tenido presente y no lo fue (Gala, 2017: 86-87).

Finalmente, tampoco se prevé respecto de las prestaciones de paternidad un subsidio no contributivo para proteger aquellos casos que no logren reunir los requisitos mínimos de cotización y quedan expulsados de la cobertura pública (Aguilera y Gil, 2010: 96). Otra diferencia más respecto de la prestación por maternidad donde sí que se prevé un subsidio no contributivo, con una base reguladora inferior (100 por 100 del IPREM) al subsidio por maternidad.

\section{Reflexiones finales}

Diez años después de la entrada en vigor de la LOI, resulta innegable el impacto positivo de este cuerpo normativo, en aras de lograr un mayor acercamiento hacia el principio de igualdad entre hombre y mujeres. No obstante, todavía quedan retos pendientes en el camino hacia un mayor involucramiento del sexo masculino dentro de la corresponsabilidad y el reparto igualitario de las cargas familiares.

Tras haber analizado las situaciones protegidas y los titulares de los permisos de maternidad y paternidad, su normativa y últimas tendencias jurisprudenciales, resulta evidente que todavía queda trabajo pendiente. Sin embargo, de una lectura conjunta se desprende la necesidad de cambiar el foco de atención y caminar hacia un marco garantista de permisos no tanto de la madre trabajadora, sino del otro progenitor, para que de esta manera pueda realmente fomentarse una cultura de la corresponsabilidad en el que la trabajadora pueda liberarse de la perpetuación de roles de género que, como se ha visto, siguen presentes tanto en la normativa como en la doctrina jurisprudencial.

En ese sentido, cada reducción de una garantía o protección del otro progenitor para acceder a la prestación, como sucede con las limitaciones del disfrute del otro progenitor de las prestaciones por maternidad; la situación desfavorable de las madres subrogantes respecto de los varones y su situación favorable para reconocer a los hijos en condición de padres biológicos; la falta de incentivos 
para el cumplimiento de los períodos de cotización para el acceso a las prestaciones de paternidad; el período cuantitativamente inferior del permiso de paternidad; la voluntariedad del disfrute de este último permiso, y un largo etcétera, generan una mayor carga sobre la madre trabajadora.

No obstante, en atención al bien jurídico a proteger con cada medida, resulta evidente el avance jurisprudencial hacia una corresponsabilidad de ambos sexos para con la atención del estado de necesidad que se genera por el niño en sus primeros meses de vida, y la necesidad de garantizar la efectiva satisfacción de estos cuidados. Para ello, resulta indiferente el modelo de familia o el sexo de los progenitores, adoptantes y subrogantes.

Por todo ello, en un hipotético movimiento legislativo en la materia, no resultaría desacertado diferenciar entre dos permisos diferentes atendiendo al bien jurídico a proteger (Sierra, 2017: 16). Ahora bien, sólo mediante una reforma normativa y no a través de una interpretación jurisprudencial, como así ha hecho el TS con la interpretación analógica en pro del reconocimiento de la prestación a los casos de gestación subrogada, puede acometerse un movimiento de reconocimiento o supresión de prestaciones en este sentido.

Mientras el estado de la salud de la mujer embarazada y su recuperación tras el parto resulta un derecho originario de la mujer y que sólo ella puede disfrutar; el cuidado del menor recién nacido o adoptado o acogido puede garantizarse a través de un segundo permiso que no diferenciase del sexo del progenitor, adoptante o tutor. Por ello, convendría mantener un permiso de maternidad exclusivo para la madre, dirigido a este primer bien jurídico, y desligar un segundo permiso, dirigido a garantizar el cuidado del recién nacido. Este último, habría de establecerse como un permiso de obligatorio disfrute para ambas partes, so pena de volver a incurrir en un reparto desequilibrado de las cargas familiares como consecuencia del peso de factores externos y su influencia en la decisión distributiva.

\section{Bibliografía}

Aguilera Izquierdo, Raquel, y Gil Plana, Juan (2010): Las prestaciones económicas por maternidad, paternidad y riesgo durante el embarazo y la lactancia natural, Cizur Menor (Navarra), Thomson Reuters.

Aragón Gómez, Cristina (2017): «La legalización de facto de la maternidad subrogada. A propósito de los recientes pronunciamiento de la sala de lo social del tribunal supremo con respecto a la prestaciones por maternidad», Revista de Información Laboral, 1-26.

Ballester Amparo, María Amparo (2013): La prestación de maternidad, Valencia, Tirant lo Blanch.

Brunet, Laurence (2012): El régimen de la subrogación en los Estados miembros de la UE, Dirección General de Políticas Interiores. Parlamento Europeo. Obtenido de 
http://www.europarl.europa.eu/RegData/etudes/STUD/2013/474403/IPOL-JURI_ ET(2013)474403(SUM01)_ES.pdf

Cabeza Pereiro, Jaime (2010): «La maternidad de las profesionales aseguradas por mutualidades de previsión social alternativas del RETA. Derechos del "otro progenitor»", en Borrajo Dacruz, Efrén (dir.): Mujer, Trabajo y Seguridad Social, Las Rozas (Madrid), La Ley, 345-359.

Fernández-Peinado Martínez, Alicia (2013): La prestación por maternidad, Albacete, Bomarzo.

Gala Durán, Carolina (2017): «El permiso por paternidad: Un balance tras casi diez años desde su implantación", CEF-Trabajo y Seguridad Social, 406, 57-94.

Gala Durán, Carolina (2017a): «Las novedades en el ámbito del permiso de paternidad y la prestación de maternidad subrogada», La Administración Práctica, 4, 1-6.

Gorelli Hernández, Juan (2017): «La prestación por maternidad en los casos de gestación por sustitución o maternidad subrogada (vientres de alquiler)», Aranzadi Doctrinal. Estudios, 1, 1-22.

Maneiro VÁzquez, Yolanda (2010): «Discriminación por razón de sexo en la titularidad del derecho al permiso de lactancia por el padre en el caso de que la madre no sea trabajadora por cuenta ajena. Nuevas interpretaciones a la luz de la más reciente jurisprudencia», en Borrajo Dacruz, Efrén (dir.): Mujer, Trabajo y Seguridad Social, Las Rozas (Madrid), La Ley, 232-236.

Molina Navarrete, Cristóbal (2017): «Prohibida la «nacional», ¿protegemos la «gestación/maternidad subrogada internacional» con prestaciones sociales?», CEF-Trabajo y Seguridad Social, 197-210.

Muñoz Molina, Julia (2017): «La mujer en el ordenamiento de la Seguridad Social», en SÁEz LARA, Carmen (coord.): Igualdad de género en el trabajo: estrategias y propuestas, Murcia, Laborum, 163-201.

Rodríguez Bravo de Laguna, Juan José (2015): Dimensiones juridico-laborales del derecho a la conciliación de la vida familiar y laboral, Cizur Menor (Navarra), Thomson Reuters Aranzadi.

Rodríguez Rodríguez, Emma (2017): «La maternidad subrogada como generadora de derechos de concilición laboral», CEF.-Trabajo y Seguridad Social, 45, 93-120.

Sierra Hernáiz, Elisa (2017): «La incidencia del género en la regulación legal de las prestaciones por maternidad y paternidad de la seguridad social», en BLÁzQuez Agudo, Eva María (coord.): Prestaciones de la Seguridad Social y Género, Organización Iberoamericana de Seguridad Social, 7-16. 